\title{
EL VÍNCULO UNIVERSIDAD-EMPRESA EN LAS PRÁCTICAS CURRICULARES. INVESTIGACIÓN E INNOVACIÓN
}

La interacción de la universidad con el mundo de la empresa ha constituido un eje fundamental en la modernización de la educación superior europea gracias, entre otras cuestiones, a la creciente importancia concedida a la realización de prácticas formativas integradas tanto en los estudios de Grado como de Postgrado. Formación que se ha visto incrementada, especialmente, en la última década a través del desarrollo de prácticas externas. Prueba de ello es el Real Decreto 292/2014, del 11 de julio, centrado en la regulación de las prácticas académicas externas de los estudiantes universitarios, documento que desarrolla y aclara aspectos clave de esta formación. En concreto, "(...) los objetivos de las prácticas, las entidades colaboradoras y los destinatarios, requisitos, tutorías y contenidos de los convenios de cooperación educativa" con un propósito claro: impulsar la empleabilidad de los futuros profesionales, fomentar su capacidad de emprendimiento, creatividad e innovación y dar respuesta al compromiso con la transformación económica basada en la sociedad del conocimiento, tal como se recoge en esta normativa.

Ante este requerimiento, las actuales titulaciones incluyen en sus programas gran variedad y oferta de prácticas externas, tanto curriculares como extracurriculares. Para algunas titulaciones, como es el caso de las de Educación, esta actividad formativa no es algo nuevo en el currículo de sus estudiantes. Sin embargo, para otras está suponiendo un reto y cambio importante a la hora de afrontar el desarrollo de sus títulos. Sin embargo, a pesar de la fuerza formativa que se reconoce a esta materia, aún resulta minoritaria la investigación y la innovación en este campo. De ahí que sea sumamente pertinente y necesario potenciar tanto la investigación, como los proyectos de innovación sobre las prácticas externas desarrolladas por nuestros estudiantes universitarios. Favorecer publicaciones en las que se vaya reuniendo un corpus científico y didáctico sobre esta materia, medio excelente para avalar los avances y la mejora de este proceso formativo.

De acuerdo a esta idea presentamos este monográfico centrado en las prácticas externas curriculares en las titulaciones de Educación. Se denominan prácticas curriculares aquellas que el alumnado universitario realiza de forma obligatoria y regulada por las universidades en instituciones, entidades, organismos, centros docentes o empresas. Se reconoce como una herramienta formativa idónea que facilita una interacción en un contexto real entre el estudiante y el entorno de trabajo para el que se forma. En cuanto a sus bondades se destaca, por un lado, la conexión con la realidad del ámbito profesional del estudiantado universitario en la que aplicar 
sus conocimientos, así como completar y consolidar las competencias transversales, específicas y profesionales necesarias para la inserción al mercado laboral y su desarrollo profesional. Por otro, las empresas precisan profesionales con una buena base teórica, con dominio de competencias instrumentales, interpersonales... capaces de transferir esos conocimientos y aplicarlos en escenarios complejos cada vez más cambiantes, como el que rodea al mundo empresarial. Se trata, por tanto, de que el binomio universidad-empresa logre trabajar de forma conjunta y conectada, compartiendo objetivos, valores y estrategias, generando experiencias en las que se dé cabida a la investigación y al conocimiento innovador de la universidad, lo que será susceptible de redundar en la creación, transferencia y mejora de cuestiones tan relevantes como la oportunidad de incrementar la empleabilidad.

Con este propósito el presente monográfico reúne seis experiencias de prácticas externas curriculares integradas en titulaciones vinculadas a los Grados en Magisterio, Educación Social y Pedagogía, así como al Máster Universitario de Formación del Profesorado de Secundaria. En todas ellas se reflexiona en torno a aspectos relacionados con el desarrollo, la valoración y la innovación inmersos en procesos formativos en contextos reales.

El volumen comienza con la interesante contribución de Vázquez-Cano, SeviIlano García y de Pedro Sotelo, Innovación educativa desde el Prácticum de Pedagogía, en el que se analiza las concepciones del alumnado universitario sobre la innovación educativa a partir de su proceso de trabajo en el Practicum del Grado en Pedagogía, a la vez que propone ámbitos de actuación encaminados a innovar en las aulas.

El segundo artículo, Satisfacción del alumnado y del profesorado-tutor con el Practicum del Grado de Maestro/a de Educación Infantil, de Gil Molina, contrasta la valoración de la experiencia en el periodo de prácticas del alumnado del Grado de Maestro en Educación Infantil y del profesorado-tutor de los centros escolares que les han acogido durante el Practicum.

En tercer lugar, la propuesta de Iglesias, Moncho y Lozano, Repensando la formación teórica a través del Prácticum: experiencias de una docente novel, muestra la importancia de la práctica reflexiva en la vinculación del conocimiento teórico y las experiencias de Practicum de una maestra novel.

Continua el artículo de Triviño y Requena, Investigación e Innovación educativa desde el máster de formación del profesorado de ciencias sociales a las prácticas curriculares en educación secundaria, que presenta un proyecto de aprendizaje-servicio en torno a la alfabetización audiovisual, desarrollado simultáneamente en asignaturas del Máster Universitario del Profesorado en Educación Secundaria, en la especialidad de Ciencias Sociales, y en las Prácticas Profesionales de dicho Máster.

Ruiz-Corbella, Bautista-Cerro y García-Blanco proponen un interesante estudio, Prácticas profesionales y la formación en competencias para la empleabilidad, que muestra una investigación desarrollada a lo largo de 5 cursos académicos en la que se recoge una experiencia de innovación docente dirigida al proceso de elaboración de un Proyecto Profesional por parte del alumnado del Grado en Educación Social. 
Culmina el monográfico con la propuesta Colaboración dialógica entre profesores de diversos niveles de enseñanza, de Gómez del Castillo y Aguilera Jiménez, en la que se describe una experiencia de colaboración entre docentes universitarios y de centros escolares, y estudiantes de Ciencias de la Educación, poniendo de manifiesto como fruto de esta interacción la contribución al desarrollo profesional de todos los agentes implicados.

En suma, el presente volumen ofrece al lector, por un lado, el interés e implicación del profesorado de nuestras universidades para favorecer los mejores espacios formativos en los contextos profesionales más diversos, a la vez que facilitar la necesaria interacción entre el mundo laboral y el de la formación. Por otro, una visión acerca del importante y beneficioso papel que desempeña la relación permanente y estrecha entre la universidad y la empresa en la generación y transferencia de conocimientos, y en el impulso de la innovación para el desarrollo de una educación de mayor calidad y, por ende, para el progreso de la sociedad.

Marta Ruiz-Corbella

Universidad Nacional de Educación a Distancia - UNED

Rosa Ana Alonso Ruiz

Universidad de La Rioja 